\title{
Skills Gap Challenge: How Apprenticeship Programs Address Skill Building and Educational Advancement
}

\author{
Lesley Page \\ Lewis University \\ Rachael Narel \\ Benedictine University \\ Elizabeth Belgio \\ Lewis University
}

\begin{abstract}
The job market reflects a complex set of employability issues when higher education, technical training and job fill rates are considered (Chaitanya, 2018; Moore \& Morton, 2017). As a result, skills gap or job readiness issues have emerged (Moore \& Morton, 2017), with a detrimental impact on employers and organizations (e.g., lack of productivity, performance, etc.) as well as employees (e.g., turnover, poor person- job fit, etc.). To help fill the void created by this mismatch, organizations are investing in apprenticeship programs. While the benefits of these programs are significant, opportunities exist to maximize overall apprentice performance and success.
\end{abstract}

Keywords: apprenticeship programs, skills gap, realistic job preview, person-environment fit, person-job fit, person-organization fit

\section{INTRODUCTION}

The current job market reflects a complex set of employability issues when higher education, technical training, and job fill rates are considered (Chaitanya, 2018; Moore \& Morton, 2017). Institutions of higher education and hiring employers often come to this intersection from different angles. As a result, issues such as a "skills gap" or higher education crisis have emerged (Hora, 2018). To heighten the intensity of this clash, there is no universal agreement about what is or is not needed for employees to be successful on the job or what is or is not the responsibility of institutions of higher education to "teach" those about to join the workforce. To complicate this further, students are often more focused on where to go to school rather than what to study (Decker, 2019). Additionally, there is not generalizability as to the skills needed across fields or disciplines. This is not a one-sided argument, as there is more to the skills gap dilemma than meets the eye (Moore \& Morton, 2017).

What does become clear, however, is the issue faced by employers when trying to hire new employees and employees who desire to contribute on the job. This has resulted in what many label as a skills gap or job readiness issue (Moore \& Morton, 2017). A skills gap refers to the fact that employers seek new hires 
who are able to productively contribute on the job (Chaitanya, 2018; Decker, 2019) yet once employed hiring managers find that new employees are not adequately able to make those contributions. This disparity can have a detrimental impact on employers and organizations (e.g., lack of productivity, performance, ROI, etc.) as well as employees (e.g., turnover, poor person-job fit, unrealistic job expectations, low morale, etc.).

To help fill the void created by this mismatch, work skills can be gained from formalized classroom training or experiential / work-based learning (WBL) (Decker, 2019). Training can allow students/employees to develop needed skills for job success before they begin their job. As a result, institutions of higher education can rethink how coursework is delivered to help foster the technical and interpersonal skills needed on the job (Davidson, 2017).

Institutions of higher education have been formed to educate traditional students by building a foundation of skills in liberal arts knowledge (e.g., history, philosophy, literature, math, etc.). This has been the foundation for learning within colleges and universities for over a century (Davidson, 2017), and most universities will market this curriculum as their general education requirements. As the job market has evolved and more jobs require a college degree, there is pressure in higher education to ensure students become effective and productive employees. It is from this viewpoint that the tension between higher education and employability begins (Davidson, 2017; Moore \& Morton, 2017).

Some argue that the broad base learning from a liberal arts curriculum and general education background is not enough to teach the technical skills students need to begin their careers (Kulkarni \& Kulkarni, 2019). Others present a counter argument that foundational core learning is how we develop teams, work collaboratively, and learn to communicate (Hora, 2018). The purpose of this paper is not to resolve such conflict but to acknowledge that essential, personal skills are often what is lacking in today's digital age learning (Smith, 2018). For years these same points were raised as educators distinguished between traditional (aged 18-22 years) and non-traditional (aged 22+ years) learners. Economic challenges, an increase in tuition, and markedly higher student loan debt have been just a few of the forces increasing the growth in the non-traditional student population. Historically, educators have believed that nontraditional students needed to learn the essential interpersonal career-focused skills, while traditional students needed technical skills training (Smith, 2018). That is no longer the case. All students (and jobready employees) ultimately need to learn both (Ibrahim, Boerhannoeddin \& Bakare, 2017), what Smith (2018) describes as personal, purposeful, and powerful learning (p.8).

\section{Technical Skills Training}

Technical skills are associated with discipline specific tools taught in a chemistry lab, art studio, or finance class, for example. Technical skills ensure an educated student (or employee) is able to tackle work outcomes required on the job. Traditionally technical skills are taught in the classroom, therefore are considered the responsibility of educators. Based on today's complex organizational demands, it is becoming evident that technical skills are also developed on the job. For several years after the economic downturn of 2008, market analysts found fault that people could not find jobs because they were not appropriately trained to do so. Others argue that the issue was access to jobs rather than training for them (Hora, 2018)

Nevertheless, the common ground lies in the notion that technical skills are required by most employers for a variety of jobs, therefore institutions of higher education should focus on providing this training. The skills gap issue sees the challenge of curriculum design as one seeking to bridge the gap between two domains: similarity of tasks vs. content of learning and application (Moore \& Morton, 2017). Moyer \& Graebe (2018) studied this issue with nurses, discussing the dilemma as a "practice gap." A practice gap conceptually is the distance from where things are now to where they could/should be (p. 52). Of course, there is direct alignment to the skills gap and issue of job readiness. Miller (1990) created a diagram to visually portray this learning cycle in the nursing field, which applies to other disciplines as well (see Figure $1)$. 
FIGURE 1

MILLER'S (1990) FRAMEWORK FOR CLINICAL ASSESSMENT

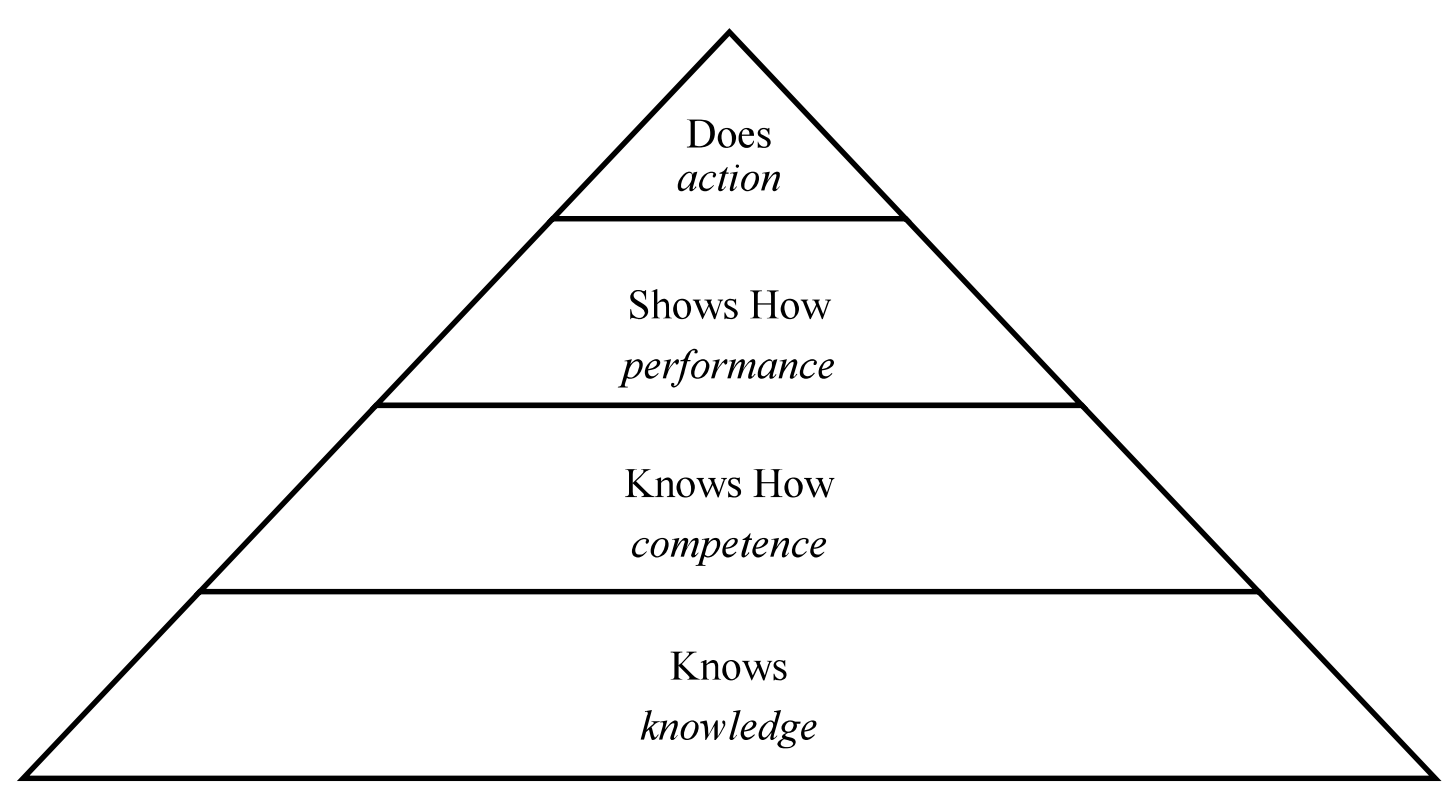

A growing trend reflects employers providing technical training on the job so that the technical skills learned are a direct match to those needed by the organization. Of course, students need to have the foundational understanding of concepts, systems, and theories that lie beneath this technical knowledge (presumably learned within a classroom) yet employers can fine-tune the training to best align with the needs of the job and organizational processes. This indicates the skills gap goes beyond a mismatch of only technical skills (Chaitanya, 2018). In fact, more than $80 \%$ employers indicate that the essential skills associated with leadership are the most desirable attributes they seek in new hires (NACE, 2016).

\section{Essential/Interpersonal Skills Training}

In addition to technical skills, most hiring employers indicate that their best performing employees are those who can interact with each other using clear communication, fostering teamwork and collaboration, and solving problems using a variety of different techniques. These essential skills, often called "soft" skills, describe how employees work together to achieve organizational outcomes. Parlamis \& Monnot (2019) cleverly say the soft stuff is actually the hard stuff. Many researchers agree that soft skills are critical to the success of any profession (Kulkarni \& Kulkarni, 2019).

Ibrahim et al. (2017) indicate that the time employers spend on technical or hard skills development should be redirected to essential skills training instead, as those soft skills are most often associated with on the job performance and employee productivity. Doing so will help organizations to create a highperformance work culture based on open lines of communication, team development and effective problem solving (see Table 1). In fact, Ibrahim et al. (2017) argue that over-reliance on technical and managerial skills comes at the expense of much needed human or soft skills which could jeopardize the long-term company mission. 
TABLE 1

EXAMPLES OF ESSENTIAL INTERPERSONAL SKILLS

\begin{tabular}{|l|l|}
\hline Essential Skill & Definition \\
\hline Communication & Ability to speak clearly and directly to others. \\
\hline Conflict Resolution & $\begin{array}{l}\text { Willingness to resolve discrepancies and conflict in a positive and } \\
\text { productive way. }\end{array}$ \\
\hline Team Skills & $\begin{array}{l}\text { Working to be part of a team in which multiple people work toward the } \\
\text { same outcome. }\end{array}$ \\
\hline Leadership & Open to influencing and directing others with positive intent. \\
\hline Decision Making & $\begin{array}{l}\text { Ability to use creativity and innovation to solve problems and make } \\
\text { decisions. }\end{array}$ \\
\hline Emotional Intelligence & $\begin{array}{l}\text { Willingness to take responsibility for self-awareness/control and the } \\
\text { awareness of others. }\end{array}$ \\
\hline
\end{tabular}

Kulkarni \& Kulkarni (2019) found that the essential, interpersonal skills associated with collaborative and communicative exchanges are critical for success in any profession. This contrasts with technical skills which may be job or discipline specific. Essential skills reflect an employee's ability to work well with others, which is paramount as a team activity and collaborative projects gain in frequency and necessity (Nahavandi, 2015). In fact, today's organizations are more complex than ever requiring employees to have skills with complex problem solving, decision-making, and innovation. When working together, employees can generate more creative and effective solutions than when working alone. This reflects the results-driven rather than authoritative nature of our organizational needs and what it takes to be successful in fostering collaborative work cultures as well as the common trend of doing more with less (Nahavandi, 2015). According to Hora (2018), the interpersonal skills needed to fill this gap are "... deeply shaped by culture, gender, discipline and even geography" (p. 24). The skills gap crisis brings to light the need to assess the person-culture fit as it relates to job success as person-job alignment is critical for outcomes focused on employee retention and satisfaction (Hora, 2018).

Building essential skills takes time and energy. Yet the value can be substantial. When employees have interpersonal skills and can work together, there is a gain for both the organization and the individual. The skills gap tends to foster a negative attribution of problems to professors in education not teaching the rights things or students who choose certain non-technical majors. Hora (2018) argues this is not that the case as a recent AAC\&U survey found that $85 \%$ of employers value broad-based learning and the creation of a foundational knowledge set that can foster essential interpersonal skills. The challenge may be for higher education to find new teaching methods to allow students to practice building these skills inside and outside the classroom. Kulkarni \& Kulkarni (2019) discuss such methods as projects that require students to work collaboratively, case studies with real-world application, team building and leadership skill development, and encouraging students to interact with each other via dialog (to strengthen communication and problemsolving skills). Ibrahim et al. (2017) discuss the concept of knowledge transfer and emphasize how educators can enhance essential skills development through specific learning activities and exercises in the classroom which include demonstrations, discussions, debates, role-playing, case studies, gaming, and electronic media.

In summary, the skills gap debate opens the conversation to what is really important: job readiness. Employers and educators share the responsibility to train students/employees by developing the technical and interpersonal skills necessary to achieve personal and organizational results. The challenge then becomes, how do organizations bridge this gap? 


\section{APPRENTICESHIP PROGRAMS}

Apprenticeship programs have emerged as one method to fill this gap. Apprenticeship programs are a specific job training strategy that combines on-the-job training with instructional activities, typically provided in a classroom (Collins, 2016). While utilized more frequently for job opportunities in Europe, apprenticeships are becoming more common in the U.S. (Fuller \& Sigelman, 2017). Typically thought of as a pathway in a trade or technical field (e.g., electricians, plumbers, welders, etc.), apprentice programs are more recently emerging in what have traditionally been professional or "white collar" jobs as well (e.g., technology, computer systems, engineering, insurance, etc.). Statistics from the United States Department of Labor (2018) highlight a 56\% growth in apprenticeships since 2013, with over 10,800 new programs created between 2013 and 2018. In FY 2018, over 238,000 apprentices entered an apprenticeship program and 71,700 graduated from an apprenticeship program (United States Department of Labor, 2018).

The benefits of an apprenticeship can be significant, both for the apprentice and the organization. In a study completed by Accenture (2019), 71\% of individuals involved in a professional apprenticeship stated that the apprenticeship program led to a better job, citing benefits including increased salary, acquisition of needed skills, an expanded professional network and more interesting work. While there is a significant investment required for organizations to develop and implement an apprenticeship program, apprentices accept lower wages during training and organizations benefit by enabling more proficient workers over the long-term (Bilginsoy, 2003). These benefits are only realized, however, if the apprentices remain with the organization. Given less than half of registered apprentices complete training (Bilginsoy, 2003), the high rate of attrition creates an opportunity to further analyze factors for improved organizational success.

\section{Person, Organization, and Job Fit}

In the past two decades, researchers have implied organizational success is likely contingent on the compatibility between employees and organizations (Bretz \& Judge, 1994). The lack of congruence between employees and various aspects of their organizations may result in employee turnover. KristofBrown, Zimmerman, and Johnson (2005) define Person-Environment fit as "the compatibility between an individual and a work environment that occurs when their characteristics are well matched" (p. 281).

Different types of interactions in the workplace shape people's perception of "fit" (Kristof-Brown et al., 2005). In order to conceptualize fit aligned to how it is experienced, Kristof-Brown et al. (2005) investigated four types of person-environment (PE) fit: person-job (PJ), person-organization (PO), persongroup (PG), and person-supervisor (PS) fit. They also explored the relationships between the four types of PE fit with job satisfaction, organizational commitment, satisfaction with coworkers, and satisfaction with supervisors, and found that the four types of fit were moderately related to each other; emphasizing the uniqueness of each fit type.

\section{Person-Organization Fit}

Notably, the Person-Organization Fit concept and origin can be traced back to a several seminal theories, such as Murray's (1938) Need Pressed Theory, Byrne's (1971) Similarity Attraction Theory, Tajfel and Turner's (1985) Social Identity Theory, Dawis and Loftquist's (1984) Work Adjustment Theory, and Schneider's (1987) Attrition-Selection-Attraction Framework.

Murray's (1938) pioneering research suggested that an employee's attitude and success was largely dependent upon the relationship between the needs and demands of his or her job in relation to his or her own needs in performing the job. Through his findings, Murray indicated that an individual's reactions are a direct response to one's work environment, and an employee may mold and conform to a position if the requirements of the task are in congruence with their personal desires and beliefs (Murray, 1938).

Byrne's Similarity-Attraction Theory (1971) reflected thoughts in the research of Murray in that people searching for employment would seek out potential employers that exhibit characteristics aligned with their own. A few of these characteristics that employees would seek out in an organization were similar social, physical, and status traits (Byrne, 1971). Byrne firmly advocated that the interaction between an individual 
and employing organization must exhibit parallel values and beliefs; otherwise, the employee would not be invested in the organization, and satisfaction and performance would be negatively impacted.

Tajfel and Turner (1985) added to this exploration of "fit" in organizations with their Social Identity Theory. Their studies showed that the values of an organization could actually shape the employee, which was in contrast to the complementary relationship that had been discussed to date. Tajfel and Turner (1985) posited that when employees hold their organization's beliefs as valuable, they will identify with the organization in a desirable fashion. Their research also uncovered that when people hold their employing organization in positive regard, they were more inclined to stay with the organization long-term. Further research on this topic also illustrated once again performance gains and gains in satisfaction.

This topic of Person-Organization Fit was again addressed by Dawis and Lofquist in 1984 through their Work Adjustment Theory. They believed that organizational outcomes are achieved when an employee's work environment expectations are met within their organization. The Work Adjustment Theory states that if there is a fluid and positive reciprocating relationship between an individual and work environment, both sides will flourish and prosper from the harmonious union (Dawis \& Loftquist, 1984).

Schneider, Goldstein, and Smith's (1995) attraction-selection-attrition (ASA) framework adds goal congruence as an important dimension of Person-Organization Fit. According to the ASA framework, individuals will be attracted to organizations whose goals are instrumental in their own. Thus, goal congruence involves the similarity between the goals of the organization and those of the organization's employees. If aligned, individuals will have a higher probability of goal attainment, higher job performance, and higher satisfaction and commitment.

In a similar vein to many of these studies, Chatman (1989) found that Person-Organization Fit is actually "the congruence between the norms and values of organizations and the values of persons" ( $p$. 339). Her work was rooted in the notion that behavior is the response of an individual to his or her surroundings. As such, she studied the effect that individuals have upon the situations in which they exist and felt that individuals are active participants in their choice of environmental situations and the outcomes as a result of placing themselves in that situation (Chatman, 1989). In effect, her research looks at both the forest and the trees of the Person-Organization theory in how the employee relates to the organization as a whole as well as each interaction in their work life.

As has been seen through this historical discussion, essentially Person-Organization Fit theory posits that there are characteristics of organizations that have the potential to be congruent with characteristics of employees, and that employees' attitudes, behaviors, and performance will be influenced by the degree of congruence or "fit" between employees and organizations. However, despite the general consensus that Person-Organization Fit involves the compatibility between individuals and their organizations, the exact nature of this compatibility has resulted in much confusion in defining P-O fit (Kristof, 1996). PersonOrganization Fit has been defined in a variety of ways, as can be seen here, including value congruence, goal congruence, needs-supplies fit, and demands abilities fit (Murray, 1938; Byrne, 1971; Tajfel \&Turner, 1985; Dawis \& Loftquist 1984; Schneider, 1987; Chatman, 1989).

\section{Person-Job Fit}

Person-Job Fit is the relationship between an individual's characteristics and those of the tasks performed at work. This is different from Person-Organization Fit which focused on similarities and congruence in attributes between the employee and organization. Person-Job Fit is much more focused on the fulfillment of specific qualities, task, or skill needs of a person and organization. Due to the amount of empirical research and in-practice applications focused on selecting well-qualified applicants, person-job fit is one of the most commonly researched areas of person-environment fit (Kristof, 1996). It is also generally found to be easier to define and measure as a match between an employee's skills, knowledge, and abilities, individual needs, and job demands with what the job itself provides (O'Reilly, Chatman, \& Caldwell, 1991).

Person-Job Fit can be further conceptualized in two distinct ways: demands-abilities (DA) fit and needssupplies (NS) fit (Edwards, 1991). Both forms of job fit are extensions of the complimentary fit distinction defined as when the person or the organization requires the other to supply a distinct need that is missing 
(Cable \& DeRue, 2002). Although demands-abilities and needs-supplies fit types are two very different conceptualizations of Person-Job Fit, they have been shown to exhibit an independent influence on important workplace outcomes (Edwards, 1991).

Demands-abilities (DA) fit refers to the compatibility between a person's knowledge, skills, and abilities (KSA's) and the KSA's needed to perform the job (Edwards, 1991). In recruiting, DA fit is used by organizations to evaluate if a person's abilities are compatible with the demands of the role or position. These can be ascertained in various ways such as resumes, reference checks, and other selection processes.

Needs-Supplies (NS) fit is the extent to which a person's needs, desires, and preferences are fulfilled by what a job provides to them. A person's needs may include the attainment of psychological needs, goals, and interests (Kristof, 1996). There has been some questioning of the overlap between this and PersonOrganization Fit, however, this is at the job level and not the organization level. Job supplies include fiscal, physical, and psychological resources provided by the organization (Edwards, 1991).

Cable \& DeRue (2002) suggested that the Person-Job Fit is significantly related to several work-related attitudes and behaviors such as job satisfaction, quality of work-life, employee turnover, and positive adjustment in new organizations. Additionally, Person-Job Fit helps with job satisfaction and organizational commitment while reducing turnover intention.

\section{FINDING THE “FIT” IN EARLY STAGES OF EMPLOYMENT}

People evaluate "fit" as they make crucial employment decisions while navigating through all stages of organizational life with a company (Cable \& DeRue, 2002). Researchers have hypothesized that different stages of employment cause a person to evaluate fit in alternative ways due to the fact that they have different needs at different points of employment. These needs are satisfied by particular types of workplace fit more than others. For example, Person-Organization Fit may have a stronger influence on attitudes and intentions at the job seeker stage and less of an influence at the incumbent stage of employment. As a result, the importance a person assigns to different aspects of the work environment can change over time (Chapman, Uggerslev, Carrol, Piasentin, \& Jones, 2005).

Again, here we will focus primarily on Person-Organization and Person-Job Fit. Several studies have shown that Person-Organization Fit is consistently related to attraction to an organization (Cable \& Judge, 1996; Carless, 2005; Chapman et al., 2005; Ehrhart \& Ziegert, 2005), job acceptance intentions (Bretz \& Judge, 1994; Judge \& Bretz, 1992) and hiring recommendations (Cable \& Judge, 1996). Research has also demonstrated the significance of Person-Organization Fit to other positive work-related outcomes such as employee commitment, employee turnover, and job satisfaction (Greguras \& Diefendorff, 2009). As discussed, from a recruitment perspective, Person-Job Fit is commonly operationalized as the fit between applicant knowledge, skills, and abilities (KSAs) and job demands (Caldwell \& O'Reilly, 1990). Over time, this fit is also important as one continues in their role and looks to job enlargement, enrichment or movement to other positions within the organization.

\section{Job Seeker}

According to signaling theory (Spence, 1973), aspects of the recruiting and selection process signal peripheral clues to a job seeker. These clues help a prospective worker determine what their experience will be like as an employee of an organization. Signaling theory provides a means of understanding how job seekers form initial reactions to a company in the absence of complete information. When job seekers experience perceptions of workplace fit, they are more likely to experience positive attitudes and intentions towards the organization (Cable \& Judge, 1996; Chapman et al., 2005; Kristof-Brown et al., 2005).

\section{Person-Organization Fit and Job Seekers}

As discussed earlier, job seekers have a fundamental desire to seek out organizations embodying shared similarities. Social Identity Theory (Tajfel \& Turner, 1985) can be once again used to explain the pursuit of similarity in the workplace. As a result of the similarity perceived to exist, people classify themselves and others into social categories such as race, age, gender, religious affiliations, and organizational 
membership (Tajfel \& Turner, 1985). As a result of social identification, the organization becomes embedded as a part of the individual's social identity. Thus, potential employees are attracted to employers sharing similar qualities because these organizations are congruent with their social identity.

\section{Person-Job Fit and Job Seekers}

Accurate and realistic information about the details of a job helps to enable job seekers decide if their own knowledge, skills and abilities (KSA's) match important job requirements. The more information available about the role helps provide a complete picture of what it would be like to work for an organization. Prospective employees with more information about a job engage in more informed selfselection decisions than less informed job seekers. Researchers have suggested the existence of a linear relationship between the amount of job information provided to applicants and organizational attraction and intentions to pursue the organization (Chapman et al., 2005).

\section{THE INCUMBENT STAGE OF EMPLOYMENT}

A person's experience of workplace fit can be very different once they have become established within the organization compared to that of a job seeker. While prospective job seekers experience the workplace through various information sources that provide a preview of an employer, incumbents experience the work environment first-hand. Their experiences at this stage can lead to a very different evaluation of fit.

An evaluation of workplace fit for an incumbent is often prompted by negative workplace experiences such as conflicting values, job demands, or conflict with others (Edwards, 1991). During these experiences, a person engages in more intense, longer, and more frequent periods of thoughts of their perceived compatibility with the work environment. When employees feel as though there is a misfit with important components of their workplace, they are more likely to leave the company.

\section{Person-Organization Fit and Incumbents}

When Person-Organization compatibility exists, employees are able to identify with the organization and its members (Tajfel \& Turner, 1985). Just as job seekers make efforts to classify themselves as potential members of an organization based on perceived similarities, organizational incumbents also have a fundamental desire to fit in and relate to other members. Going back to foundational theory, recall Byrne (1971) hypothesized that people desire to interact with others similar to themselves in order to validate their own self-concept. People feel good about what they believe, value, and strive to obtain in their work lives when they interact with others sharing the same values, beliefs, and goals. As an established employee, workers now have a better sense of interacting as part of an organizational citizen and truly experiencing the culture and organizational values. As the literature has discussed, these compatible values are the key to P-O fit leading to higher performance, satisfaction, and retention (Cable \& Judge, 1996, 1997; Chatman, 1989).

\section{Person-Job Fit and Incumbents}

When an established worker is equipped, or believes they are equipped, with the necessary skills to perform a job, they will be more satisfied with the job itself (Dawis \& Lofquist, 1984). The positive relationship between P-J fit and job satisfaction has been empirically demonstrated by various studies (Caldwell and O'Reilly, 1990; O'Reilly, Caldwell, and Mirable, 1992) as well as meta-analytic results of Kristof-Brown et al. (2005), which found person-job fit to be strongly correlated with incumbent attitudes of job satisfaction and turnover intentions. Positive incumbent attitudes such as these may be attributed to an incumbent's confidence that they will be successful on the job (Gregarus \& Diefendorff, 2009).

The belief that a person feels they can accomplish a desired outcome or task is the basis of Bandura's (1986) construct of self-efficacy. People with high degrees of self-efficacy are less likely to focus on their personal deficiencies and are more likely to cope (Bandura, 1986). Gregarus and Diefendorff (2009) suggested Person-Job Fit and self-efficacy are conceptually very similar constructs. People with high 
Person-Job Fit should similarly experience improved coping, learning, motivation, and adjustment capabilities.

In summary, understanding the complexity of Person-Organization and Person-Job Fit allows both employees (at various stages of their career life cycle) and organizations to make decisions about recruitment, placement and ongoing development on the job. Apprenticeship programs can benefit by considering the necessity of "fit" when it comes to reaping the benefits of the program and long-term persistence on the job. One way to ensure "fit" is maximized is to provide a realistic job preview to the job seeker/incumbent.

\section{REALISTIC JOB PREVIEW}

The realistic job preview (RJP) is a technique designed to present job applicants with an authentic view of organizational life and the job for which they are applying by including negative as well as positive information (Wanous, 1973). Hakel (1982) defined RJPs as “... presenting all pertinent information without distortion" (p. 153). More recently, Earnest, Allen, and Landis (2011) defined RJPs as "programs, materials, and/or presentations that provide applicants with realistic and balanced (positive and negative) information about a job" (p.866). In recent years, RJPs have received considerable research attention, and use in practice, to evaluate their effects in the recruiting and hiring process.

Weitz (1956) is credited as being one of the first to propose that providing job applicants with a realistic picture of the job would reduce turnover. This early study in this research was focused on insurance agents and showed that the group who received a realistic preview booklet prior to job acceptance, compared to those who received a regular recruiting booklet, experienced $30 \%$ less turnover for the first six months of employment.

Nearly two decades later, Wanous (1973) coined the term "realistic job preview". In his various studies, Wanous found that providing realistic job information did not affect job acceptance, but did affect job survival, with the realistic job information group experiencing less turnover and higher job satisfaction than the control group. Overall, he concluded that met expectations were the foundational psychological mechanism behind the efficacy of realistic recruitment information, as opposed to applicant self-selection. In addition, Wanous (1978) proposed a comprehensive conceptual model in which he described how providing realistic information to job applicants may affect various organizational outcomes (see Figure 2). He explained that providing applicants accurate information about a job prevents later disillusionment, related to both job attitudes and job survival. As shown in Figure 2, the model proposes four primary underlying psychological mechanisms by which RJPs should reduce turnover: self-selection, met expectations, ability to cope, and air of honesty. 
FIGURE 2

PSYCHOLOGICAL PROCESSES UNDERLYING THE EFFECTIVENESS OF THE RJP

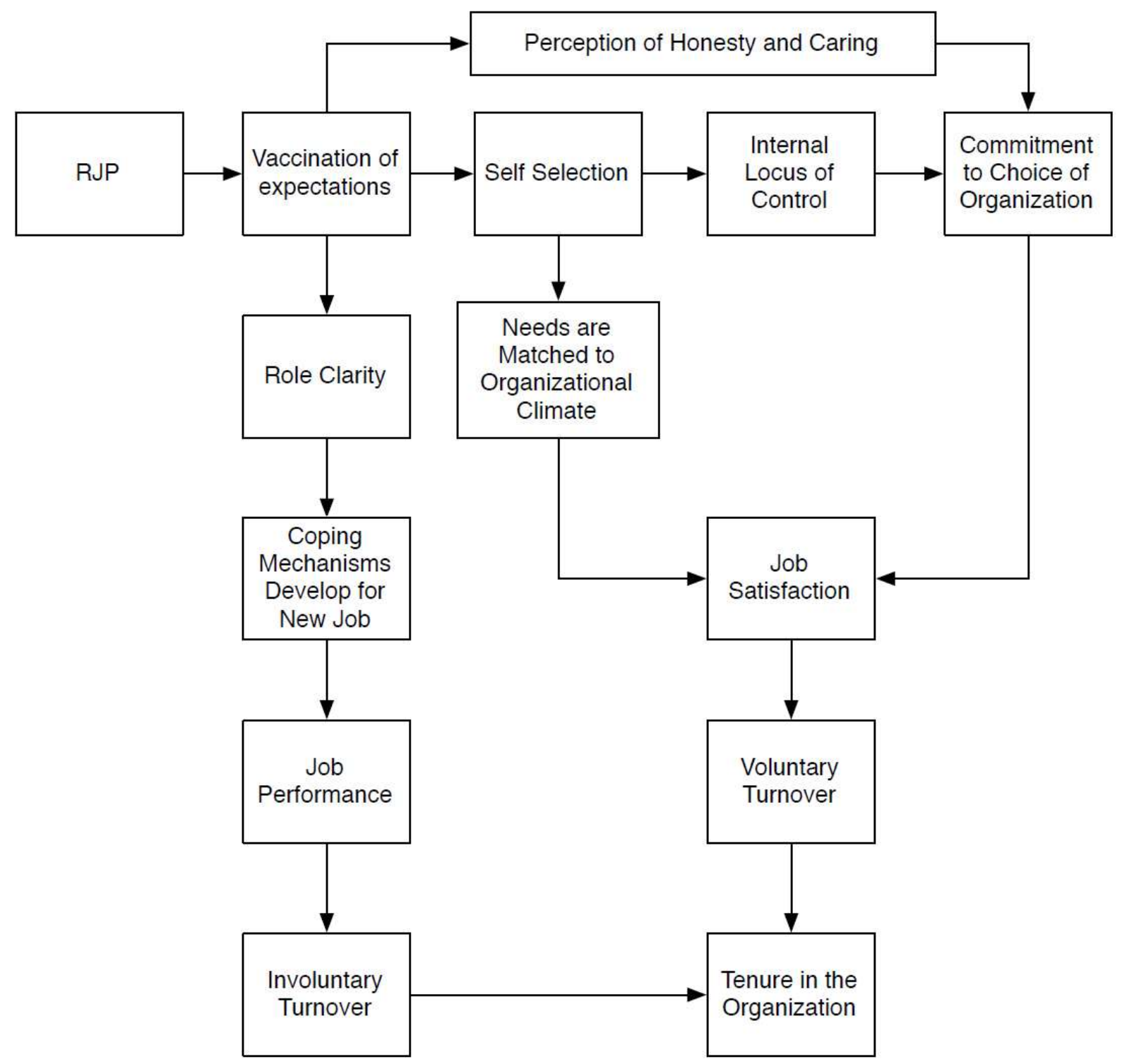

(Wanous, 1978)

RJPs can help candidates make appropriate job choices and reduce the negative impact of lack of "fit" between the candidate, the position and the organization (Phillips, 1998). The outcomes that are commonly associated with RJPs are perceptions of organizational climate, organizational commitment, improved coping ability, initial expectations, job satisfaction, job performance, self-selection, and job survival (Phillips, 1998; Premack \& Wanous, 1985). The employee's perception of an organization's climate includes the organization's trustworthiness, supportiveness, honesty and candidness. The use of an RJP during the recruitment process has been found to lead to more positive perceptions of the climate (Premack \& Wanous, 1985).

As retention is a key factor considered, it is important to note that the same results apply to organizational commitment. Candidates who received RJPs showed increased levels of organizational commitment as measured by the Organizational Commitment Questionnaire (Porter, Steers, Mowday, \& 
Boulian, 1974). Phillips (1998) reported RJPs have demonstrated the ability to reduce turnover and increase job survival. Phillips also reported that RJPs negatively impact turnover, specifically voluntary turnover. As we consider Person-Organization and Person-Job Fit, that is a key finding.

Overall, the results through these studies indicated by Premack and Wanous (1985) and Philips (1998) in providing candidates with an RJP were that they: enabled candidates the opportunity to make the correct job choice, created more satisfaction on the job because of the fit between expectations and the real organization culture, climate, and working conditions, and increased overall commitment to the organization.

\section{CONCLUSION}

The current paper draws on the research presented related to a skills gap crisis, higher education, technical and interpersonal skills training, person-organization and person-job fit and realistic previews to assess a professional apprenticeship program in terms of benefit to the employee, organization and evaluation of important organizational outcomes such as on the job performance, satisfaction and retention.

With on-the-job skill building inherent within apprenticeship programs, apprentices have a multi-year opportunity to develop critical skills necessary for the job, fully explore organizational and job fit, and benefit from a realistic job preview. The unique structure of apprenticeship programs can support apprentices in making a correct job choice, leading to increased satisfaction and commitment. However, these benefits can only be realized if the apprenticeship program enables apprentices to fully understand the organizational climate and participate in the long-term job choice. Apprenticeship programs without that transparency and inclusion may not result in the same long-term benefits associated with increased satisfaction and commitment.

\section{REFERENCES}

Accenture white paper. (2019). Apprenticeships: From community college to promising tech career. Retrieved from https://www.accenture.com/_acnmedia/PDF-111/Accenture-ApprenticeshipsFrom-CC-To-Promising-Tech-Career.pdf

Bandura, A. (1986). Social foundations of thought and action: A social cognitive theory. Englewood Cliffs, NJ: Prentice Hall.

Bilginsoy, C. (2003). The Hazards of Training: Attrition and Retention in Construction Industry Apprenticeship Programs. ILR Review, 57(1), 54-67.

Bretz, R.D., \& Judge, J.A. (1994). Job search behavior of employed managers. Personnel Psychology, 7 , 275-301.

Byrne, D. (1971). The attraction paradigm. New York, NY: Academic Press.

Cable, D.M., \& DeRue, D.S. (2002). The convergent and discriminant validity of subjective fit perceptions. Journal of Applied Psychology, 87, 875-884.

Cable, D.M., \& Judge, T.A. (1996). Person-organization fit, job choice decisions, and organizational entry. Organizational Behavior and Human Decision Processes, 67(3), 294-311.

Cable, D.M., \& Judge, T.A. (1997). Interviewers' perceptions of person-organization fit and organizational selection decisions. Journal of Applied Psychology, 82(4), 546-561.

Caldwell, D.F., \& O'Reilly, C.A. (1990). Measuring person-job fit with a profile-comparison process. Journal of Applied Psychology, 75(6), 648-657.

Carless, S.A. (2005). Person-job fit versus person-organization fit as predictors of organizational attraction and job acceptance intentions: a longitudinal study. Journal of Occupational and Organizational Psychology, 78, 411-429.

Chaitanya, K.E. (2018). Soft skills to complement professional students' technical skills to enhance their employability rate. Language in India, 18(12), 52-60. 
Chapman, D.S., Uggerslev, K.L., Carroll, S.A., Piasentin, K.A., \& Jones, D.A. (2005). Applicant attraction to organizations and job choice: A meta-analytic review of the correlates of recruiting outcomes. Journal of Applied Psychology, 90(5), 928-944.

Chatman, J. (1989). Improving interactional organizational research: A model of person organization fit Academy of Management Review, 14, 333-349.

Collins, B. (2016). Apprenticeship in the United States: Frequently asked questions. CRS Report R44174. Congressional Research Service. Washington, DC

Davidson, C.N. (2017). The new education: How to revolutionize the university to prepare students for a world in flux. New York, NY: Basic Books.

Dawis, R., \& Lofquist, L. (1984). A psychological theory of work adjustment: An individual differences model and its applications. Minneapolis, MN: University of Minnesota Press.

Decker, D. (2019). Student perceptions of higher education and apprenticeship alignment. Education Sciences, 9(2). https://doi.org/10.3390/educsci9020086

Earnest, D.R., Allen, D.G., \& Landis, R.S. (2011). Mechanisms linking realistic job previews with turnover: A meta-analytic path analysis. Personnel Psychology, 64, 865-897.

Edwards, J.R. (1991). Person-job fit: A conceptual integration, literature review, and methodological critique. In C.L. Cooper \& I.T. Robertson (Eds.), International review of industrial and organizational psychology (vol. 6, pp. 283-357). New York: Wiley.

Ehrhart, K.H., \& Ziegert, J.C. (2005). Why are Individuals Attracted to Organizations? Journal of Management, 31, 901-919.

Greguras, G.J., \& Diefendorff, J.M. (2009). Different fits satisfy different needs: linking personenvironment fit to employee commitment and performance using self-determination theory. Journal of Applied Psychology, 94(2), 465-477.

Hakel, M.D. (1982). Employment interviewing. In K.M. Rowland \& G.R. Ferris (Eds.), Personnel Management (pp. 129-155). Boston: Allyn and Bacon, Inc.

Hora, M.T. (2018, Spring). Beyond the skills gap: How the vocationalist framing of higher education undermines student, employer and societal interests. Liberal Education.

Ibrahim, R., Boerhannoeddin, A., \& Bakare, K.K. (2017). The effect of soft skills and training methodology on employee performance. European Journal of Training and Development, 41(4), 388-406. DOI: 101108/EJTD-08-2016-0066

Judge, T.A., \& Bretz, R.D. (1992). Effects of work values on job choice decisions. Journal of Applied Psychology, 79, 937-949.

Kristof, A.L. (1996). Person-organization fit: An integrative review of its conceptualizations, measurement, and implications. Personnel Psychology, 49, 1-49.

Kristof-Brown, A.L., Zimmerman, R.D., \& Johnson, E.C. (2005). Consequences of individuals' fit at work: a meta-analysis of person-job, person-organization, person-group, and person supervisor fit. Personnel Psychology, 58(2), 281-342.

Kulkarni, S., \& Kulkarni, D.G. (2019). Gap analysis of soft skills in the curriculum of higher education (A case study of management institutes in Karnataka. Advances in Management, 12(1), 64-67.

Miller, G. (1990). The assessment of clinical skills/competence/performance. Academic Medicines, 65, S63-S67.

Moore, T., \& Morton, J. (2017). The myth of job readiness? Written communication, employability and the 'skills gap' in higher education. Studies in Higher Education, 42(3), 591-609. http://dx.doi.org/10.1080/03075079.2015.1067602

Moyer, A., \& Graebe, J. (2018). Identifying the underlying educational needs that contribute to the professional practice gap. The Journal of Continuing Education in Nursing, 49(2), 52-54. doi: 10.3928/00220124-20180116-02.

Murray, H. (1938). Explorations in personality. New York, NY: Oxford University Press.

Nahavandi, A. (2015). The art and science of leadership ( $7^{\text {th }}$ edition). Essex, England: Pearson Education Limited. 
National Association of Colleges and Employers (NACE) Job Outlook Report. (2016). The Attributes Employers Seek on a Candidate's Resume. Retrieved from https://www.naceweb.org/talentacquisition/candidate-selection/the-attributes-employers-seek-on-a-candidates-resume/

O'Reilly, C.A., Caldwell, D.F., \& Mirable, R. (1992). A profile comparison approach to person-job fit: More than a mirage. Academy of Management Proceedings, pp. 237-241.

O'Reilly, C.A., Chatman, J.M., \& Caldwell, D.F. (1991). People and organizational culture: A profile comparison approach to assessing person-organization fit. Academy of Management Journal, 34(3), 487-516.

Parlamis, J., \& Monnot, M.J. (2019). Getting into the CORE: Putting an end to the term "soft skills." Journal of Management Inquiry, 28(2), 225-227. DOI: 10.1177/1056492618818023

Phillips, J. (1998). Effects of realistic job previews on multiple organizational outcomes: A meta-analysis. Academy of Management Journal, 41, 673-690.

Porter, L.W., Steers, R.M., Mowday, R.T., \& Boulian, P.V. (1974). Organizational commitment, job satisfaction, and turnover among psychiatric technicians. Journal of Applied Psychology, 59, 603609.

Premack, S., \& Wanous, J. (1985). A meta-analysis of realistic job preview experiments. Journal of Applied Psychology, 70, 706-719.

Schneider, B. (1987). The people make the place. Personnel Psychology, 40, 437-453.

Schneider, B., Goldstein, H.W., \& Smith, D.B. (1995). The ASA framework: An update. Personnel Psychology, 48, 747-773.

Smith, P. (2018). Free-range learning in the digital age: The emerging revolution in college, career and education. New York, NY: SelectBooks.

Spence, A.M. (1973). Job Market Signaling. Quarterly Journal of Economics, 87, 355-374.

Tajfel, H., \& Turner, J.C. (1985). The social identity theory of intergroup behavior. In S. Worchel \& W.G. Austin (Eds.), Psychology of intergroup relations (2nd ed., pp. 7-24). Chicago: NelsonHall.

United States Bureau of Labor Statistics. (2019). Job Openings and Labor Turnover. Retrieved December 21, 2019, from https://www.bls.gov/news.release/jolts.nr0.htm

United States Department of Labor. (2019). Apprenticeship: Data and statistics. Retrieved December 20, 2019, from https://www.doleta.gov/oa/data_statistics.cfm

Wanous, J.P. (1973). Effects of a realistic job preview on job acceptance, job attitudes, and job survival. Journal of Applied Psychology, 58, 327-332.

Weitz, J. (1956). Job expectancy and survival. Journal of Applied Psychology, 40, 245-247. 